\title{
Changes of Calcium Binding Protein Expression in Spinothalamic Tract Neurons After Peripheral Inflammation
}

\author{
D. SOJKA ${ }^{1}$, G. ZACHAROVA ${ }^{1}$, D. SPICAROVA ${ }^{1}$, J. PALECEK ${ }^{1}$ \\ ${ }^{1}$ Department of Functional Morphology, Institute of Physiology, Academy of Sciences of the Czech \\ Republic, Prague, Czech Republic
}

Received August 12, 2010

Accepted August 16, 2010

\begin{abstract}
Summary
Specific neuronal populations are known to express calcium binding proteins (CBP) such as calbindin (CB), parvalbumin (PV) and calretinin (CR). These CBP can act as calcium buffers that modify spatiotemporal characteristics of intracellular calcium transients and affect calcium homeostasis in neurons. It was recently shown that changes in neuronal CBP expression can have significant modulatory effect on synaptic transmission. Spinothalamic tract (STT) neurons form a major nociceptive pathway and they become sensitized after peripheral inflammation. In our experiments, expression of CBP in STT neurons was studied in a model of unilateral acute knee joint arthritis in rats. Altogether 377, 374 and 358 STT neurons in the segments L3-4 were evaluated for the presence of $C B, P V$ and CR. On the contralateral (control) side $11 \%, 9 \%$ and $47 \%$ of the retrogradely labeled STT neurons expressed $C B, P V$ and $C R$, respectively. On the ipsilateral (arthritic) side there was significantly more CB (23\%) and PV (25\%) expressing STT neurons, while the number of CR positive neurons (50\%) did not differ. Our results show increased expression of fast (CB) and slow (PV) calcium binding proteins in STT neurons after induction of experimental arthritis. This suggests that change in CBP expression could have a significant effect on calcium homeostasis and possibly modulation of synaptic activity in STT neurons.
\end{abstract}

\section{Key words}

Calbindin - Parvalbumin - Calretinin - Synaptic plasticity • Arthritis

\section{Corresponding author}

J. Paleček, Department of Functional Morphology, Institute of Physiology, v.v.i., Academy of Sciences of the Czech Republic. Vídeňská 1083, 14220 Prague 4, Czech Republic. Fax: +420 241062 488. E-mail: palecek@biomed.cas.cz

\section{Introduction}

Specific antibodies to calcium binding proteins (CBP) such as calbindin (CB), parvalbumin (PV) and calretinin (CR) have been used for a long time by neuroanatomists to stain different populations of neurons in the brain. However, recently we started to question the functional significance of the presence of CBP in different neuronal types (Schurmans et al. 1997, Klapstein et al. 1998, D'Orlando et al. 2001, 2002, Schwaller et al. 2002, 2009, Schmidt et al. 2003). CBP can be divided into two major groups, one that translates calcium concentration into activation of different signaling pathways and a second one that serves mainly as a calcium buffer that modifies spatiotemporal characteristics of intracellular calcium transients (see review by Schwaller 2009). CB, PV and CR are considered to act primarily as calcium buffers that due to different biophysical properties affect calcium transients in different ways. In this respect PV is considered to be a slow onset buffer while $\mathrm{CR}$ and $\mathrm{CB}$ are fast buffers. CBPs thus play a major role in calcium homeostasis in neurons and other cells (Schwaller et al. 2002, 2009).

Increased intracellular calcium concentration due to calcium influx and/or its release from internal stores is considered to be one of the key mechanisms for modulation of synaptic plasticity and sensitization of dorsal horn neurons. The physiological effect of the calcium is dependent on activation of Ca-dependent second messengers and is thus affected by the spatiotemporal characteristics of the calcium concentration change (Neher 1998). The presence or absence of calcium binding proteins with different biophysical properties affects the Ca-buffering capacity 
of the cell (Neher and Augustine 1992, Chard et al. 1993, Paleček et al. 1999, Burnashev and Rozov 2005) and could affect synaptic properties and especially different forms of synaptic plasticity that are known to be $\mathrm{Ca}$ dependent. This was recently confirmed at GABAergic synapses in the cerebellum, where paired pulse stimuli evoked synaptic depression in wild type $\mathrm{PV}+/+$ mice, but facilitation in PV-/- mice that did not express PV (Caillard et al. 2000, Rozov et al. 2001, Muller et al. 2007). Spinothalamic tract (STT) neurons form the major nociceptive pathway and are known to become sensitized under different pathological conditions (Willis 2001). It is thought that increased calcium influx due to peripheral injury induced activity in nociceptive primary afferents, is important for sensitization of STT neurons. Changes of CBP expression, changing calcium buffering properties in these neurons, could thus significantly affect modulation of nociceptive signaling at the spinal cord level.

In our previous experiments, we have reported a decrease of PV expression in spinal cord dorsal horn, presumably also including GABAergic interneurons, after induction of experimental arthritis (Zachařová et al. 2009). In this current study we have studied expression of $\mathrm{CB}, \mathrm{CR}$ and PV in retrogradely labeled STT neurons under the control conditions and in a model of experimental arthritis known to induce sensitization of STT neurons (Dougherty et al. 1992) and significantly increase afferent activity coming from the knee joint afferent fibers (Neugebauer and Schaible 1990, Schaible et al. 2002).

\section{Materials and Methods}

All experiments were approved by the local Institutional Animal Care and Use Committee and were consistent with the guidelines of the International Association for the Study of Pain, the National Institutes of Health Guide for the Care and Use of Laboratory Animals and the European Communities Council Directive of 24 November 1986 (86/609/EEC). Adult male Wistar rats (250-350 g) were kept in plastic cages with soft bedding, free access to food and water and were maintained on a $12 \mathrm{~h}$ light, $12 \mathrm{~h}$ dark cycle.

\section{Retrograde labeling of STT and PSDC neurons}

Animals were anesthetized with ketamine $(100 \mathrm{mg} / \mathrm{kg}$ i.p., Narkamon, Zentiva) and xylazine (10 mg/kg i.m., Rometar, Zentiva) for retrograde labeling of spinothalamic neurons. Stereotaxic access to the thalamus was acquired through small surgical penetrations of the skull, similar to previously published methods (Paleček et al. 2003). Retrograde fluorescent tracer (dextran labeled with Cy2, Molecular Probes) was injected into the lateral thalamic nuclei on both sides $(0.5 \mu \mathrm{l}$, at coordinates caudal $2-4 \mathrm{~mm}$ and lateral 3 from the bregma point and $6 \mathrm{~mm}$ deep from the surface). The tracer was injected using a glass micropipette mounted on a micromanipulator and connected to an air pressure delivery system. The wounds were surgically closed and the animals were left to recover for 7-10 days before they were used for further experimental procedures. The locations of the retrograde tracer injections in the thalamus were verified on histological sections at the completion of the experiment.

\section{Induction of experimental arthritis}

In the experimental group of animals $(n=9)$, arthritis was induced unilaterally by intra-articular injection of $3 \%$ mixture of kaolin and carrageenan in physiological saline solution $24 \mathrm{~h}$ before the perfusion. The animals were anesthetized with sodium pentobarbital (50 $\mathrm{mg} / \mathrm{kg}$ i.p.) and one knee joint was injected. The animals were left to recover in their home cages. Arthritis was not induced in a control group of animals $(n=3)$.

\section{Immunohistochemical analysis}

8-11 days after the retrograde tracer injection the rats were deeply anesthetized with sodium pentobarbital $(70 \mathrm{mg} / \mathrm{kg}$ i.p.) and transcardially perfused with heparinized physiological saline solution followed by an ice cold solution of $4 \%$ paraformaldehyde. The fixed spinal cords and brains were removed and placed overnight in the $4 \%$ paraformaldehyde solution. Spinal cord segments were marked in the ventral part with a fine pin on one side. The spinal segments L3-4 were cryoprotected in $30 \%$ sucrose solution and then serially sectioned at $30 \mu \mathrm{m}$ thickness by cryocut (Leica). The serial sections were placed in three vials so that slices in each one were separated by at least $60 \mu \mathrm{m}$ tissue thickness $(2$ slices). This enabled staining for all three proteins and prevented double-counting of STT neurons. Each of the vials was then used for immunostaining with a different specific antibody to calbindin (monoclonal, Sigma), parvalbumin (monoclonal, Sigma) or calretinin (polyclonal, Sigma). Slices were washed in phosphate buffered saline (PBS) incubated in $3 \%$ donkey serum (Jackson Immuno, USA) and incubated overnight at room temperature with primary antibody under constant slow 
motion. On the next day, slices were washed, incubated with the corresponding secondary antibody (Texas Red, Jackson Immuno), washed, dried and mounted with DPX (Fluka). In control experiments no positive stain was observed when primary antibody was omitted in the process. The histological slides were analyzed under a fluorescent microscope (Olympus AX) with appropriate filters for Cy2 and Texas Red fluorescent dyes. The slides were evaluated for the presence of retrogradely labeled STT neurons and expression of CBP. Location of the cells was marked on a schematic spinal cord section drawing. The number of labeled STT neurons in the L3-4 spinal segments was determined and the percentage of those expressing CBP calculated. Percentage of STT neurons expressing $\mathrm{CBP}$ was averaged in the experimental group. A paired t-test was used for evaluation of statistical differences between the ipsilateral and contralateral sides.
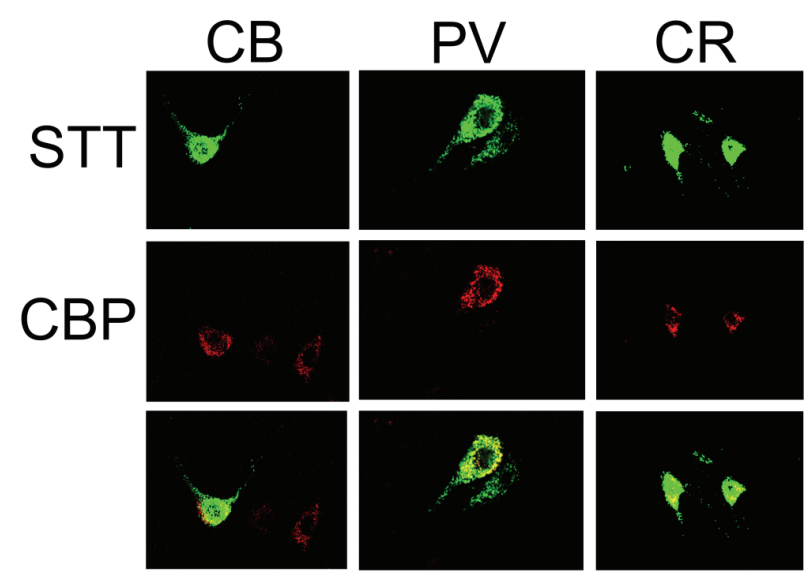

Fig. 1. Soma and main dendritic branches of STT neurons retrogradely labeled with green fluorescent dextran were clearly visible on the spinal cord sections. Immunohistochemical staining for different calcium binding proteins (CBP, red) was observed in some of the STT neurons, as is evident from the combined pictures in the last row.
CB

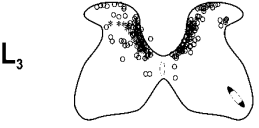

$\mathrm{L}_{4}$

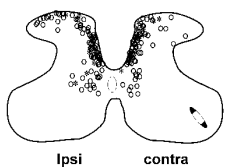

PV
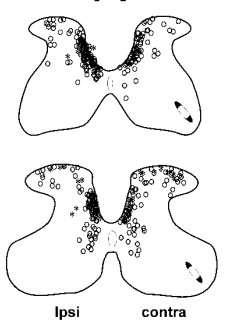

CR
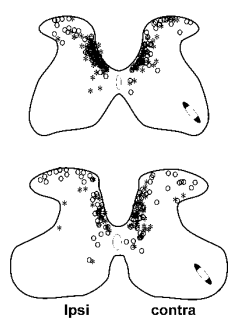

Fig. 2. The distribution of STT neurons retrogradelly labeled from thalamus and immunostained for calbindin (CB), parvalbumin (PV) and calretinin (CR) in lumbar spinal cord segments $24 \mathrm{~h}$ after arthritis induction. The location of STT neurons without positive stain is depicted by circles and those positively stained with stars on ipsilateral (ipsi) and contralateral (contra) side to the arthritis induction.

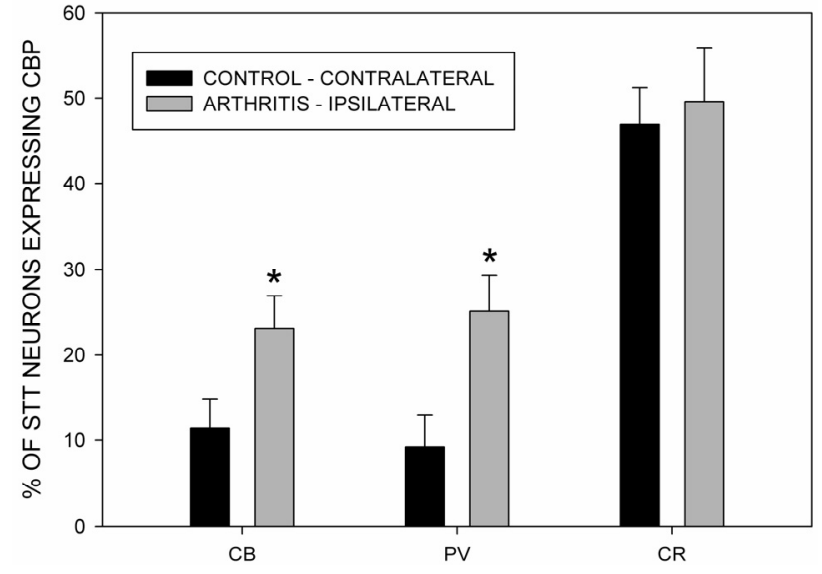

Fig. 3. The percentage of STT neurons positively immunostained for Calbindin (CB), Parvalbumin (PV) and Calretinin (CR) 24 hours after arthritis induction ipsilaterally and contralaterally to the inflamed knee joint. There was a significantly higher number of STT neurons positively stained for CB and PV, while the number of STT neurons stained for CR did not change. (* $\mathrm{p}<0.05$, paired t-test).

\section{Results}

The retrogradely labeled somata and main dendritic branches of the STT neurons were easily observed due to the presence of green fluorescent dextran (Fig. 1). Most of the retrogradely labeled neurons were located in the medial dorsal horn grey matter, while a smaller population was found in the superficial laminae (Fig. 2). The red immunostain for the CBP was clearly visible in a number of neurons (Fig. 1). On average there were 42 retrogradely labeled STT neurons evaluated for each CBP in the histological slides from the L3-4 segments in each animal. Altogether 377, 374 and 358 STT neurons in the segments L3-4 were evaluated for presence of $\mathrm{CB}, \mathrm{PV}$ and $\mathrm{CR}$, respectively, in nine experimental animals. On the control side, contralateral to the knee inflammation, 11, 9 and $47 \%$ of the labeled STT neurons expressed $\mathrm{CB}$, PV or CR (Fig. 3). This corresponds well with the expression of CBP in STT neurons in the group of control intact animals $(n=3)$, where arthritis was not induced (CB $7 \%$, PV $13 \%$, CR $57 \%$ ). In the experimental animals there was a significant increase in the number of $\mathrm{CB}$ and $\mathrm{PV}$ expressing STT neurons on the ipsilateral side (23\% and $25 \%$ ) when compared to the contralateral side, $24 \mathrm{~h}$ after the arthritis induction (Fig 3). The number of CR expressing STT neurons (50\%) did not change significantly. The distribution of CBP expressing STT neurons did not differ distinctly in their dorsal horn distribution from the population that did not label for CBP (Fig. 2). 


\section{Discussion}

The expression of three calcium binding proteins (CB, PV and CR) in STT neurons in control rats and in rats after unilateral peripheral knee inflammation was studied. In control animals and on the contralateral side in the rats with unilateral knee inflammation, about half of the retrogradely labeled STT neurons stained for CR, while CB and PV immunostain was present in a smaller population of neurons $(11 \%, 9 \%)$. In animals with the knee arthritis, the number of the CB- and PV-positive STT neurons on the ipsilateral side significantly increased $(23 \%, 25 \%)$, while the number of CR-positive STT neurons did not change. To our knowledge this is the first study reporting the extent of CBP expression in STT neurons in the rat. The number of lamina I STT neurons in monkeys showing $\mathrm{CB}$ immunoreactivity was reported to be higher (78\%), most likely due to species and labeling differences (Craig et al. 2002). The colocalization of CBPs was not assessed in the present study, but previous immunohistochemical studies revealed partial colocalization of $\mathrm{CB}$ with $\mathrm{CR}$ in cultured dorsal horn neurons (Albuquerque et al. 1999). On the contrary, $\mathrm{CB}$ and PV in the superficial dorsal horn of the rat spinal cord appears to be present in separate neuronal populations (Yoshida et al. 1990, Magnusson et al. 1996).

In our experiments there was increased number of STT neurons expressing CB ipsilaterally to the knee inflammation. In other experimental models it was shown that $\mathrm{CB}$ immunoreactive neurons are relatively resistant to the neurotoxic effect of glutamate and NMDA (D'Orlando et al. 2001, 2002). The increase of CB might thus theoretically protect the STT neurons against glutamate excitotoxicity associated with the excessive peripheral signaling after peripheral inflammation (Schaible and Schmidt 1985, Sorkin et al. 1992, Westlund et al. 1992). In hippocampal neurons increased expression of $\mathrm{CB}$ suppressed posttetanic potentiation (Chard et al. 1995). Increased expression of CB in STT neurons could counteract their sensitization following the development of knee arthritis (Dougherty et al. 1992).

In the spinal cord dorsal horn, PV was shown to be present in a population of inhibitory interneurons (Yamamoto et al. 1989, Laing et al. 1994). This was also supported by detailed morphological studies localizing dense parvalbumin immunoreactivity to the inner part of lamina II of the rat superficial dorsal horn (Antal et al. 1990, Ren and Ruda 1994). In our previous study, we found a decrease of PV expression in the neuropil of the lumbar spinal cord dorsal horn, but not in the lumbar dorsal root ganglion neurons ipsilaterally to the experimental knee arthritis (Zachařová et al. 2009, Zachařová and Paleček 2009). As one possible explanation we have suggested a decrease of PV expression in presynaptic processes of GABAergic interneurons, which could potentiate GABAergic inhibitory circuits, counteracting the enhanced nociceptive signaling from the inflamed periphery. Increase of PV expression in the STT projection neurons found in the present study may attenuate STT neurons sensitivity to afferent input and thus reduce nociceptive transmission to supraspinal centers. Both of these mechanisms could contribute to the modulation of spinal neuronal activity and counteract the excessive neuronal activity coming from the periphery under inflammatory conditions.

The number of CR-positive STT neurons did not change in our experimental model. Nevertheless, their relatively high proportion in control as well as in the arthritic rats supports a possible important role of CR in spinal sensory functions. Putative involvement of $\mathrm{CR}$ in the spinal nociceptive and proprioceptive pathways was previously suggested on the basis of the morphological distribution pattern of CR in the rat spinal cord, showing the densest staining of both cell bodies and fibers in the superficial laminae and in the lateral spinal and cervical nuclei (Ren et al. 1993). Some recent studies also indicate neuromodulatory (Schurmans et al. 1997) and neuroprotective (Henzi et al. 2009) CR functions. CR is reportedly expressed in almost all dorsal horn lamina II neurons possessing the Kv 4.3 alpha subunit of voltagegated $\mathrm{K}^{+}$channels, which are supposed to be involved in the central sensitization (Huang et al. 2005). High colocalization of $\mathrm{CR}$ in spinal cord lamina II was also reported with a potent proinflammatory compound, leukotriene B4 (Chiba et al. 2006), and possible cooperation of these two molecules in neuromodulatory function was suggested.

CBPs as mobile calcium buffers substantially influence neuronal synaptic processes. $\mathrm{CB}$ and $\mathrm{CR}$ are in general considered to be fast buffers with rapid $\mathrm{Ca}^{2+}$ binding characteristics and reducing especially the peak of the calcium transient. However, it was shown for both the $\mathrm{CB}$ and $\mathrm{CR}$ that they could act also as slow buffers under different circumstances (Chard et al. 1995, Klapstein et al. 1998, for review see Schwaller 2009). PV is thought to act as a slow calcium buffer, accelerating 
mainly the initial decay of the calcium transient, as was shown in rat dorsal root ganglion neurons (Chard et al. 1993), supported by recent studies on bovine chromaffin cells (Lee et al. 2000) and especially by studies on transgenic mice (Caillard et al. 2000, Schmidt et al. 2003, Collin et al. 2005, Muller et al. 2007, for review see Schwaller 2009). Great impact of PV on synaptic plasticity was demonstrated using PV null mutant mice, where PV deficiency increased residual $\mathrm{Ca}^{2+}$ in GABAergic presynaptic terminals at the interneuron/Purkinje cell synapse (Collin et al. 2005) and mediated conversion of paired-pulse induced depression into paired-pulse facilitation (Caillard et al. 2000).

Marked elevation of PV and CB expression in STT neurons after peripheral inflammation and high expression of CR suggest that mobile cytoplasmic CBPs acting as modulators of endogenous free calcium levels could have a profound effect on complex regulatory mechanisms of nociceptive transmission at the spinal cord level. However, the precise role of CBPs in modulation of nociceptive signaling in STT neurons needs to be established.

\section{Conflict of Interest}

There is no conflict of interest.

\section{Acknowledgements}

Supported by GACR 305/09/1228, MSMT CR LC554, AV0Z 50110509.

\section{References}

ALBUQUERQUE C, LEE CJ, JACKSON AC, MACDERMOTT AB: Subpopulations of GABAergic and nonGABAergic rat dorsal horn neurons express $\mathrm{Ca}^{2+}$-permeable AMPA receptors. Eur J Neurosci 11: 2758-2766, 1999.

ANTAL M, FREUND TF, POLGAR E: Calcium-binding proteins, parvalbumin- and calbindin-D 28k-immunoreactive neurons in the rat spinal cord and dorsal root ganglia: a light and electron microscopic study. J Comp Neurol 295: 467-484, 1990.

BURNASHEV N, ROZOV A: Presynaptic $\mathrm{Ca}^{2+}$ dynamics, $\mathrm{Ca}^{2+}$ buffers and synaptic efficacy. Cell Calcium 37: 489495, 2005.

CAILLARD O, MORENO H, SCHWALLER B, LLANO I, CELIO MR, MARTY A: Role of the calcium-binding protein parvalbumin in short-term synaptic plasticity. Proc Natl Acad Sci U S A 97: 13372-13377, 2000.

CHARD PS, BLEAKMAN D, CHRISTAKOS S, FULLMER CS, MILLER RJ: Calcium buffering properties of calbindin D28k and parvalbumin in rat sensory neurones. J Physiol Lond 472: 341-357, 1993.

CHARD PS, JORDAN J, MARCUCCILLI CJ, MILLER RJ, LEIDEN JM, ROOS RP, GHADGE GD: Regulation of excitatory transmission at hippocampal synapses by calbindin D28k. Proc Natl Acad Sci U S A 92: 5144-5148, 1995.

CHIBA Y, SHIMADA A, SATOH M, SAITOH Y, KAWAMURA N, HANAI A, KEINO H, IDE Y, SHIMIZU T, HOSOKAWA M: Sensory system-predominant distribution of leukotriene A4 hydrolase and its colocalization with calretinin in the mouse nervous system. Neuroscience 141: 917-927, 2006.

COLLIN T, CHAT M, LUCAS MG, MORENO H, RACAY P, SCHWALLER B, MARTY A, LLANO I: Developmental changes in parvalbumin regulate presynaptic $\mathrm{Ca}^{2+}$ signaling. J Neurosci 25: 96-107, 2005.

CRAIG AD, ZHANG ET, BLOMQVIST A: Association of spinothalamic lamina I neurons and their ascending axons with calbindin-immunoreactivity in monkey and human. Pain 97: 105-115, 2002.

D'ORLANDO C, FELlay B, SCHWALlER B, SAliCiO V, BLOC A, GOTZOS V, CELIO MR: Calretinin and calbindin D-28k delay the onset of cell death after excitotoxic stimulation in transfected P19 cells. Brain Res 909: $145-158,2001$.

D'ORLANDO C, CELIO MR, SCHWALLER B: Calretinin and calbindin D-28k, but not parvalbumin protect against glutamate-induced delayed excitotoxicity in transfected N18-RE 105 neuroblastoma-retina hybrid cells. Brain Res 945: 181-190, 2002.

DOUGHERTY PM, SLUKA KA, SORKIN LS, WESTLUND KN, WILLIS WD: Neural changes in acute arthritis in monkeys. I. Parallel enhancement of responses of spinothalamic tract neurons to mechanical stimulation and excitatory amino acids. Brain Res Brain Res Rev 17: 1-13, 1992. 
HENZI T, BLUM WV, PFEFFERLI M, KAWECKI TJ, SALICIO V, SCHWALLER B: SV40-induced expression of calretinin protects mesothelial cells from asbestos cytotoxicity and may be a key factor contributing to mesothelioma pathogenesis. Am J Pathol 174: 2324-2336, 2009.

HUANG HY, CHENG JK, SHIH YH, CHEN PH, WANG CL, TSAUR ML: Expression of A-type K channel alpha subunits $\mathrm{Kv} 4.2$ and $\mathrm{Kv} 4.3$ in rat spinal lamina II excitatory interneurons and colocalization with painmodulating molecules. Eur J Neurosci 22: 1149-1157, 2005.

KLAPSTEIN GJ, VIETLA S, LIEBERMAN DN, GRAY PA, AIRAKSINEN MS, THOENEN H, MEYER M, MODY I: Calbindin-D28k fails to protect hippocampal neurons against ischemia in spite of its cytoplasmic calcium buffering properties: evidence from calbindin-D28k knockout mice. Neuroscience 85: 361-373, 1998.

LAING I, TODD AJ, HEIZMANN CW, SCHMIDT HH: Subpopulations of GABAergic neurons in laminae I-III of rat spinal dorsal horn defined by coexistence with classical transmitters, peptides, nitric oxide synthase or parvalbumin. Neuroscience 61: 123-132, 1994.

LEE SH, SCHWALLER B, NEHER E: Kinetics of $\mathrm{Ca}^{2+}$ binding to parvalbumin in bovine chromaffin cells: implications for $\mathrm{Ca}^{2+}$ transients of neuronal dendrites. J Physiol Lond 525: 419-432, 2000.

MAGNUSSON A, DAHLFORS G, BLOMQVIST A: Differential distribution of calcium-binding proteins in the dorsal column nuclei of rats: a combined immunohistochemical and retrograde tract tracing study. Neuroscience 73: 497-508, 1996.

MULLER M, FELMY F, SCHWALLER B, SCHNEGGENBURGER R: Parvalbumin is a mobile presynaptic $\mathrm{Ca}^{2+}$ buffer in the calyx of held that accelerates the decay of $\mathrm{Ca}^{2+}$ and short-term facilitation. $J$ Neurosci 27: 22612271, 2007.

NEHER E: Vesicle pools and $\mathrm{Ca}^{2+}$ microdomains: new tools for understanding their roles in neurotransmitter release. Neuron 20: 389-399, 1998.

NEHER E, AUGUSTINE GJ: Calcium gradients and buffers in bovine chromaffin cells. $J$ Physiol Lond 450: 273-301, 1992.

NEUGEBAUER V, SCHAIBLE HG: Evidence for a central component in the sensitization of spinal neurons with joint input during development of acute arthritis in cat's knee. J Neurophysiol 64: 299-311, 1990.

PALEČEK J, LIPS MB, KELLER BU: Calcium dynamics and buffering in motoneurones of the mouse spinal cord. J Physiol 520: 485-502, 1999.

PALEČEK J, PALEČKOVÁ V, WILLIS WD: Postsynaptic dorsal column neurons express NK1 receptors following colon inflammation. Neuroscience 116: 565-572, 2003.

REN K, RUDA MA: A comparative study of the calcium-binding proteins calbindin-D28K, calretinin, calmodulin and parvalbumin in the rat spinal cord. Brain Res Brain Res Rev 19: 163-179, 1994.

REN K, RUDA MA, JACOBOWITZ DM: Immunohistochemical localization of calretinin in the dorsal root ganglion and spinal cord of the rat. Brain Res Bull 31: 13-22, 1993.

ROZOV A, BURNASHEV N, SAKMANN B, NEHER E: Transmitter release modulation by intracellular $\mathrm{Ca}^{2+}$ buffers in facilitating and depressing nerve terminals of pyramidal cells in layer $2 / 3$ of the rat neocortex indicates a target cell-specific difference in presynaptic calcium dynamics. J Physiol Lond 531: 807-826, 2001.

SCHAIBLE HG, SCHMIDT RF: Effects of an experimental arthritis on the sensory properties of fine articular afferent units. J Neurophysiol 54: 1109-1122, 1985.

SCHAIBLE HG, EBERSBERGER A, VON BANCHET GS: Mechanisms of pain in arthritis. Ann N Y Acad Sci 966: 343-354, 2002.

SCHMIDT H, STIEFEL KM, RACAY P, SCHWALLER B, EILERS J: Mutational analysis of dendritic $\mathrm{Ca}^{2+}$ kinetics in rodent Purkinje cells: role of parvalbumin and calbindin D28k. J Physiol Lond 551: 13-32, 2003.

SCHURMANS S, SCHIFFMANN SN, GURDEN H, LEMAIRE M, LIPP HP, SCHWAM V, POCHET R, IMPERATO A, BOHME GA, PARMENTIER M: Impaired long-term potentiation induction in dentate gyrus of calretinin-deficient mice. Proc Natl Acad Sci U S A 94: 10415-10420, 1997.

SCHWALLER B: The continuing disappearance of "pure" $\mathrm{Ca}^{2+}$ buffers. Cell Mol Life Sci 66: 275-300, 2009.

SCHWALLER B, MEYER M, SCHIFFMANN S: 'New' functions for 'old' proteins: the role of the calcium-binding proteins calbindin D-28k, calretinin and parvalbumin, in cerebellar physiology. Studies with knockout mice. Cerebellum 1: 241-258, 2002. 
SORKIN LS, WESTLUND KN, SLUKA KA, DOUGHERTY PM, WILLIS WD: Neural changes in acute arthritis in monkeys. IV. Time-course of amino acid release into the lumbar dorsal horn. Brain Res Brain Res Rev 17: 3950, 1992.

WESTLUND KN, SUN YC, SLUKA KA, DOUGHERTY PM, SORKIN LS, WILLIS WD: Neural changes in acute arthritis in monkeys. II. Increased glutamate immunoreactivity in the medial articular nerve. Brain Res Brain Res Rev 17: 15-27, 1992.

WILLIS WD: Role of neurotransmitters in sensitization of pain responses. Ann N Y Acad Sci 933: 142-156, 2001.

YAMAMOTO T, CARR PA, BAIMBRIDGE KG, NAGY JI: Parvalbumin- and calbindin D28k-immunoreactive neurons in the superficial layers of the spinal cord dorsal horn of rat. Brain Res Bull 23: 493-508, 1989.

YOSHIDA S, SENBA E, KUBOTA Y, HAGIHIRA S, YOSHIYA I, EMSON PC, TOHYAMA M: Calcium-binding proteins calbindin and parvalbumin in the superficial dorsal horn of the rat spinal cord. Neuroscience 37: 839$848,1990$.

ZACHǍ̌OVÁ G, PALEČEK J: Parvalbumin and TRPV1 receptor expression in dorsal root ganglion neurons after acute peripheral inflammation. Physiol Res 58: 305-309, 2009.

ZACHAŘOVÁ G, SOJKA D, PALEČEK J: Changes of parvalbumin expression in the spinal cord after peripheral inflammation. Physiol Res 58: 435-442, 2009. 